\section{ON THE CORRECTION OF DEATH-RATES FOR TRADES.*}

By J. SpotTiswoode CAMERON, M.D., B.Sc., M.O.H. for Leeds.

In the decennial report of the Registrar-General for the years $187 \mathrm{r}-8 \mathrm{I}$, Dr. Ogle made an attempt to ascertain the comparative mortality from certain trades. Selecting a hundred tolerably well-defined occupations, he had the deaths which occurred amongst men between the ages of 25 and 65 engaged in those trades got out, and he compared them with the numbers living at these ages and engaged in these occupations in the whole country. Taking the death-rate so found amongst the whole male population between 25 and 65 as $x, 000$, he found the corresponding rate amongst men of the same age engaged in every kind of occupation to be 967 , whilst that of " unoccupied males," including, of course, men invalided by chronic disease, and those too weak to have ever been engaged in any active occupation, to be 2,182 . On the other hand, selecting only the male inhabitants at these ages of certain healthy districts, he placed their mortality figure at 804 . The corresponding figure amongst "occupied males" at the same ages in the hundred selected occupations varied from 556 , the mortality figure corresponding to the occupation of "clergyman, priest, minister," to 2,205 the mortality figure for inn and hotel servants.

It will be at once evident that a town which contains a very much greater proportion of clergy, and a very much smaller proportion of inn servants than the country at large might (evergthing else being equal) be expected to have a lower mortality than one containing a very small number of clergymen and a very large number of hotel servants, Any inference, however, drawn from such a circumstance might be untrue unless it took into account the relative proportion of the clergy and the inn servants in relation to that of the country as a whole, and also the comparative mortality figures for these two classes of persons.

A numerical example of the method adopted will serve as an explanation. Taking first the occupations just mentioned, in Leeds, according to the census of $189 \mathrm{I}$, we had 0.898 rninisters of religion (excluding church officers) for every 1,000 of the population. In England and Wales there were $r^{\circ} 446$ per $I_{3}, 000$. We had therefore 0.548 per 1,000 fewer members of this longlived profession in Leeds than in the country at large. Assuming that the factor 556, given by $\mathrm{Dr}$. Ogle as the comparative mortality figure for this profession at the ages of 25 to 65 , beld good through life, the recorded death-rate in Leeds would evidently have been actually higher than it ought to have been on account of the difference in the number of followers of this healthy occupation. Working this out it will be found that

\footnotetext{
* From Dr. Cameron's Annual Report for 1893.
}

the death-rate of Leeds should be multiplied by the factor $0.99975^{67}$, to allow for this deficiency of clergy in our midst.

Again, there were in Leeds 553 men (or boys over 10) employed as inn servants, and 46,364 in England and Wales. These numbers correspond to $I .505$ and $I, 599$ respectively per $I, 000$ of the total population, a deficit in Leeds of 0.094 per I,000. As Dr. Ogle's comparative mortality figure was 2,205 , Leeds gained slightly by having somewhat fewer persons engaged in this unhealthy occupation, and the observed deate-rate requires to be multiplied by I'000 I 45 . The result from these two occupations is therefore that for the clergy and innkeepers" servants alone, our recorded deathrate should be multiplied by $0^{\circ} 99987$, which practically leaves the death-rate as it stands.

It will be at once seen that a difficulty arises if we neglect taking into account the women who act in the capacity of inn servants. In Leeds these numbered 473 , nearly as many as the men for whom we have allowed, and when we compare the number of female inn servants in Leeds with those in England and Wales, we find that we have in Leeds $0.24 \mathrm{I}$ less, per $\mathrm{I}, 000$ of the whole population, so occupied. Then comes the question, "Are we to add the minus quantity 0 "24I to the minus quantity 0.094 already dealt with, or are we to neglect it?" If we neglect it, we evidently, in this particular trade, do not make full allowance for the absence of persons engaged in an unbealthy industry. On the other hand, as it is well known that one of the principal causes of the high death. rate amongst inn servants is intemperance, is it fair to assume that the high death-rate would hold to the same extent amongst women as amongst men? If we neglect the women the factor remains for the hotel servant as already given ( $\mathrm{r}$ '000 I 45 ). If, however, we regard women as equally exposed to the risks of the trade with men, the recorded death-rate in Leeds would require for this trade alone to be multiplied by 1.0004 .

But this question of the employment of women becomes important, if we take one of the principal industries of Leeds, that of the manufacture of woollen and worsted fabrics. At the time of the census, there were 6,081 male and 8,925 female persons engaged in the manufacture of woollen, worsted, and stuff, excluding wool staplers, dyers, and printers of wool and woollen fabrics, flannel and blanket manufacturers, fullers and dealers in wool and worsted goods. In England and Wales there were ro2,050 male and I30,954 female persons engaged in the corresponding occupations, or nearly $4 \mathrm{r}$ per $\mathrm{I}, 000$ of the population in Leeds, and about 8 per $r, 000$ in the whole country. Leeds had, therefore, an excess of $32^{\prime} 786$ persons per 1,000 of the population engaged in this industry, In this case there seems no special reason for excluding the women, as there is nothing in the nature of the work very obviously rendering 
them either more or less prone to death than those of the other sex. Dr. Ogle's comparative mortality factor for woollen workers was 1032 , we therefore calculate on account of the prevalence of this industry (the mortality in which, amongst men between 25 and 65 , was in excess of the mortality amongst all men of the same ages in the proportion of $\mathrm{r}, 032$ to $\mathrm{r}, 000$ ), that allowing a similar mortality amongst women similarly employed, a correction should be made of our death rate upon this single account equivalent to multiplying it by $0.998983^{6}$.*

In a similar way the several trades for which comparative mortality figures are given by Dr. Ogle, have been got out. Where he has himself done so, however, such trades as the eleven classes of shopkeepers, or the various metal workers have been grouped together. Women workers have been included in such industries as the woollen, where they form an important part of those employed in the trade, but excluded from trades where it is evident from the statistics that the women are simply connected with the business carried on in the capacity of employer. Multiplying these factors into one another we get a general provisional trade factor of 0.986 .

This factor, bowever, deals with only a portion of the population of Leeds. It takes into account 53 per cent. of the occupied males over ro, and 35 per cent. of the occupied women. Taking the two sexes together, the factor takes account of 66 per cent. of the total occupied population over 10 , or together 3 I per cent. of the total population. What, if anything, to allow for the remaining third of the occupied persons belonging to trades for which no factor is obtainable, it is difficult to say. This 34 per cent. of occupied persons not dealt with may belong to healthier or unhealthier trades. They are to some extent allowed for, in so far as they are remainders. For instance, in Leeds, in every $x, 000$ of our population, we had $I .68$ agricultural labourers. In England and Wales the number was $24^{*} 46$. Every 1,000 of our. Leeds population, therefore, contains $22^{\circ} 78$ fewer agricultural labourers than the average proportion in the country. These $22^{\circ} 7$ must have been made up by persons otherwise occupied, and some of them belong to the 34 per cent. of occupied persons not dealt with in our calculation. Amongst unoccupied males between the ages of 25 and 65 in the whole of England and Wales, the mortality, as has been already said, was found by Dr. Ogle to be more than double that of the whole male population at the same ages. In Leeds i per cent. of the whole male population belonged to this class. In England and Wales 12 per cent. We had therefore in Leeds a very much smaller number in

\footnotetext{
* Including those of both sexes employed in the manufacture of flannels and blankets the correction factor be. comes 0.9989727 .
}

proportion of this class with a high death factor. Similarly, the unoccupied female population over ro in Leeds was 47 per cent. of the whole female population in the city. In England and Wales it was 50 per cent. While, however, the unoccupied male population has a death factor bigher than that of the whole population, this is probably due, as already pointed out, to the inclusion in this class of a large number of invalid lives. But though the halt and the maimed are possibly fewer in a manufacturing town, to a very large extent it seems probable that the smaller percentage of unoccupied persons is rather due to the want of a leisured class, so many of whom go away from our smoky atmosphere to brighter skies, and whose exclusion would increase our recorded death-rate.

Here, again, is yet another difficulty. While unoccupied men have specially a high mortality, it does not follow that the same is true of women. The census enumerator has probably been unchivalrous enough to return many women engaged in household occupations, otherwise than as domestic servants, as " unoccupied." These would of course include the infirm, but they would include also a very large proportion of the most longlived members of the community.

To make the comparisor complete, I should have wished, had time permitted, to obtain similar factors for al least the other five great towns. One thing will strike everyone, and that is that the factor $x^{\prime} 5_{52}$ (the correction according to age and sex adopted by the Registrar-General), multiplied by the factor 0.986 , obtained as above, still leaves a factor of ${ }^{\circ} \times 3^{6}$, by which the death-rate has got to be multiplied. If we are to suppose that a corresponding correction must be made for trades for which we had no comparative mortality figure, the age and sex correction factor might have to be still further reduced.*

The Bacteriology of Vaccinia, - Messrs. Ruffer and Plimmer have found a minute parasite in the vesicles of vaccinia, about four times the size of an ordinary staphylococcus. It somewhat resembles the parasite of cancer, but differs in many minor particulars. Similar organisms have been found by them in small-pox pustules. The exact relationship of these organisms to vaccinia and variola is as yet uncertain.

* The factors given above are provisional. The formula employed are as follows:-

Let $\Delta=$ required and $\delta=$ observed death-rate.

Let $n=$ number per unit of population, by which a particular trade exceeds or falls short of the average of the country, and let $f=D r$. Ogle's comparative mortality figure.

$$
\begin{aligned}
& \text { Then } \Delta=\delta\left\{\mathrm{I}-\left(\mathrm{I}-\frac{\mathrm{I}, \mathrm{OOO}}{f}\right) n\right\} \text { when } n \text { is } T \\
& \text { and } \Delta=\delta\left\{\mathrm{I}-\left(\mathrm{I}-\frac{f}{\mathrm{r}, \mathrm{COO}}\right) n\right\} \text { when } n \text { is }- \text {. }
\end{aligned}
$$

The quantity between the larger brackets is, of course, the correction factor for the trade. 